\title{
Comparison of stage/discharge rating curves derived from different recording systems: consequences for streamflow data and water management in a Mediterranean island
}

\author{
J. Fortesa $^{\text {ab }}$, J. García-Comendador ${ }^{\text {ab }}$, A. Calsamiglia ${ }^{\text {ab }}$, J.A. López-Tarazón ${ }^{\text {abcd }}$, J. Latron ${ }^{\mathrm{e}}$, B.
} Alorda $^{\mathrm{f}}$ and J. Estrany ${ }^{\mathrm{ab} *}$

${ }^{a}$ Mediterranean Ecogeomorphological and Hydrological Connectivity Research Team (http://medhycon.uib.cat), Department of Geography, University of the Balearic Islands, Carretera de Valldemossa Km 7.5 07122, Palma, Spain

${ }^{b}$ Institute of Agro-Environmental and Water Economy Research-INAGEA, University of the Balearic Islands, Carretera de Valldemossa Km 7.5 07122, Palma, Spain

${ }^{c}$ Institute of Earth and Environmental Science, University of Potsdam, Karl-Liebknecht-Straße 24/25, 14476 Potsdam-Golm, Germany

${ }^{d}$ Fluvial Dynamics Research Group, Department of Environment and Soil Sciences, University of Lleida, Av. Alcalde Rovira Roure, 191, 25198 Lleida, Spain

${ }^{e}$ Institute of Environmental Assessment and Water Research (IDAEA), Spanish Research Council (CSIC), Jordi Girona 18, 08034 Barcelona, Spain

${ }^{f}$ Department of Physics, University of the Balearic Islands, Carretera de Valldemossa Km 7.507122 , Palma, Spain

*Corresponding author: joan.estrany@uib.cat; Tel.: +34 971172362

\begin{abstract}
Obtaining representative hydrometric values is essential for characterizing extreme events, hydrological dynamics and detecting possible changes on the long-term hydrology. Reliability of streamflow data requires a temporal continuity and a maintenance of the gauging stations, which data are affected by epistemic and random sources of error. An assessment of discharge meterings' and stage-discharge rating curves' uncertainties were carried out by comparing the accuracy of the measuring instruments of two different hydrometric networks (i.e., one analogical and one digital) established in the same river location at the Mediterranean island of Mallorca. Furthermore, the effects of such uncertainties were assessed on the hydrological dynamics, considering the significant global change impacts beset this island. Evaluation was developed at four representative gauging stations of the hydrographic network with analogic $(\approx 40$ years) and digital $(\approx 10$ years $)$ data series. The study revealed that the largest source of uncertainty in the analogical (28 to $274 \%$ ) and in the digital (17-37\%) networks were the stage-discharge rating curves. Their impact on the water resources was also evaluated at the event and annual scales, resulting in an average difference of water
\end{abstract}


yields of $183 \%$ and $142 \%$ respectively. Such improvement on the comprehension of hydrometric networks uncertainties will dramatically benefit the interpretation of the long-term streamflow by providing better insights into the hydrologic and flood hazard planning, management and modelling.

Keywords: hydrometric networks; stage-discharge; metering; uncertainty; error propagation.

\section{Introduction}

River catchments are considered one of the more sensitive earth-systems to global change, due to the combination of climate change (e.g. increase of extreme storm events; Borga et al., 2010) and direct human influence (e.g. changes on land uses; García-Ruiz et al., 2011). Under this context, the hydrometric data reliability of surface water resources requires a temporal continuity and an inspection and maintenance system of the gauging stations (Shaw, 1994) to effectively detect changes. However, uncertainties in hydrological systems frequently derive from many different factors and are non-stationary because of the non-linearity of the hydrological processes (Westerberg et al., 2011; Bayazit, 2015). Due to the stochastic nature of these processes, long time series (i.e., 30 years) are required to obtaining representative hydrometric values (i.e., accurate and reliable) for characterizing extreme events, hydrological dynamics and detecting possible changes. Conversely, short data series may lead to unrepresentative values, especially in the calculation of mean flow in ephemeral and intermittent hydrological regimes (Westerberg et al., 2011). From the mid-forties to the sixties of the last century, most of the hydrometric networks used very simple measuring instruments; i.e., limnigraphs (e.g., Ward, 1967). Over the years, a substantial improvement in instrumentation has been achieved due to technological advances, allowing a higher temporal resolution monitoring (i.e., minutal intervals) of several variables (Le Coz, 2008, Volkmann et al., 2010). Despite technological advances, many of these hydrometric networks have not adopted such improvements, causing high levels of error (Mishra and Coulibaly, 2009).

The reliability of hydrometric data is affected by the transformation of water stage (hereinafter WS; $\mathrm{m}$ ) to discharge (hereinafter $\mathrm{Q} ; \mathrm{m}^{3} \mathrm{~s}^{-1}$ ) through the stage/discharge rating curves (hereinafter SDRC) into the 
qualitative range (from low to high Q conditions) of the hydrological dynamics (Gravelle, 2015). Power (Herschy, 1978; Pappenberger et al., 2006) and also polynomial (Yu, 2000) equations, characterised by physical-based parameters, are broadly used to elaborate SDRCs. This is not a unique or invariant relationship, as it is affected by different sources of error that generate uncertainty in the flow calculation (Pelletier, 1987, McMillan et al., 2012). These errors are classified according to the source that originates them, and may be random - generated by incorrect monitoring of WS, Q and/or cross-sections (Di Baldassarre and Montanari, 2009, McMillan and Westerberg, 2015)- and epistemic -related with the absolute lack of knowledge in the SDRC- due to morphological changes in the stream, seasonal vegetation growth and extrapolation of the SDRC (Rantz, 1982, Petersen-Øverleir et al., 2009, Westerberg et al., 2011).

A full comprehension of the uncertainty that affects the SDRC method requires a description of the procedure itself (Di Baldassarre and Montanari, 2009). Several methods have been used to assess the SDRC uncertainty. Le Coz et al. (2014) used a Bayesian analysis to determine the uncertainties generated by the hydraulics controls in the SDRC and the Q meterings. Reitan and Petersen-Øverleir (2011) assessed the SDRC uncertainty through a Bayesian and Markov chain Monte Carlo simulation techniques. McMillan and Westerberg (2015) assessed the uncertainty where epistemic uncertainty sources included weed growth, deposition of the bed gravels and unconfined high flows through a statistical likelihood function. It is necessary to quantitatively assess the reliability of data series generated by the hydrometric networks under non-stationarity conditions to define the best strategies in hydrological modelling and water balance calculations. Hence, Tomkins (2014) developed an analysis of the deviations in Q meterings from the SDRC, a simple robust empirically based method that can provide substantial information on SDRC uncertainty and the reliability of flow data. Despite this, few studies have investigated Q meterings and 
SDRC uncertainties also comparing the accuracy of measuring instruments of two hydrometric networks established in the same river reaches.

The present study carries out that type of assessment, in which the first network is controlled by analogical instruments (Analogical Hydrometric Network; hereinafter AHN) and compiles data series $<40$ years, while the second network is controlled by digital devices (Digital Hydrometric Network; hereinafter DHN) with data series $\approx 10$ years. The main aim of this paper is to analyse the reliability of the measured discharge by calculating the total uncertainty of the streamflow data and then quantify the individual contribution of the main different sources of uncertainty. As some of the AHN and DHN stations are located in the same gauging site, it is possible to compare their flow records, hence to evaluate the importance of their uncertainty in the quantification of the surface water resources. Such evaluation is performed at four different gauging stations of two contrasted catchments (i.e. two gauging stations per catchment) through: (1) a comparison of WS measurements from AHN and DHN recording systems; (2) an assessment of the uncertainty of the Q meterings; (3) an assessment of the uncertainty of their SDRCs; and, (4) an assessment of the SDRC effects on the water yield dynamics in the Mediterranean island of Mallorca. Finally, the global uncertainty, understood as the sum of Q meterings and SDRC uncertainties, is also assessed.

\section{Material and methods}

The assessment of Q metering's and SDRC's is performed by applying a multi-method approach focused on the integration of hydraulics and uncertainties evaluation on the surface water resources estimation (Fig. 1).

\subsection{Study area}

The island of Mallorca $\left(3,640 \mathrm{~km}^{2}\right.$; Fig. 2a) is a Mediterranean region where fluvial systems are mainly under ephemeral/intermittent hydrological regimes resulting from the combination of geology and 
Mediterranean climate, with a significant intra- and interannual variability as well as high recurrence of severe flash-flood events (Estrany and Grimalt, 2014). It is characterised by a basin-and-range topographical configuration mainly constituted by limestone geology (Jenkins et al., 1990). The hydrographic network (Fig. 2b) is formed by small catchments; only 7 exceed $100 \mathrm{~km}^{2}$, and the largest accounts for $456 \mathrm{~km}^{2}$. In mountainous areas, streams are short and very steep in headwaters; catchments are small and receive a medium-high annual precipitation (i.e., 700-1,200 mm; Pardo and Olsen, 2004). These mountainous streams represent $20 \%$ of the hydrographic network total length. In lowland areas, where annual precipitation is lower $(400-600 \mathrm{~mm})$, streams have gentler slopes with lengths representing $63 \%$ of the hydrographic network. The remaining $17 \%$ of the river streams are located on impervious materials allowing different degrees of intermittency and even punctually perennial hydrological regimes.

\subsection{Monitoring systems and validation}

The monitoring of surface hydrology on the Mallorca Island is carried out by means of the AHN (19652014), managed by the Autonomous Government of the Balearic Islands (Fig. 2b). The network design responds to the initial objective of assessing the hydrological potential of selected catchments to construct reservoirs, just 2 of the many planned were finally built and located in different river catchments to those studied here. The network was composed at 2014 of 32 stations equipped with analogical instruments (i.e., 7 limnigraphs and 25 limnimeters). All the gauging stations were built with concrete weirs which keep a uniform flow (Table 1). Limnigraph temporal resolution is 1 hour and the vertical $0.01 \mathrm{~m}$. The lack of maintenance and the structural deficiency of the AHN led the University of the Balearic Islands to implement the DHN, which has been developed in different phases since 2004 (Fig. 2b). The DHN is currently composed of 34 stations with digital pressure capacitive probes (Druck PDCR-1830-3 controlled by Campbell data-loggers CR200; Hobo Water Level U20L-04 and TruTrack WT-HR 250 water level loggers) to measure the WS by readings of 1 minute accumulating 15-minute average values providing 
continuous records.

\subsubsection{Selected gauging stations}

One of the components of the uncertainty assessment was performed by comparing the WS and the Q collected by AHN with those obtained from DHN in gauging stations placed in the same location. For this purpose, four representative gauging stations of the hydrographic network of Mallorca with long data series (40 years) were selected. Two of these official stations (i.e., Comafreda and Sant Miquel; hereinafter M1Mountainous 1- and M2-Mountainous 2-, respectively) are located in the mountainous and forested Sant Miquel catchment (Fig. 2b) whereas the other two (i.e. Sa Vall and Ses Pastores; hereinafter L1-Lowland 1and L2-Lowland 2-, respectively) are located in the lowland and agricultural Na Borges catchment (Fig. 2b). Table 1 summarizes catchment characteristics of precipitation, land uses, average annual runoff, and gauging stations recording systems type and channel bed characteristics. Further details can be read in the Experimental catchments web page.

To validate the hydrometric values generated by the recording systems it was necessary to obtain a representative range of flow rates to encompass all the situations that occur in the natural hydrological dynamics. Low, intermediate, high and extreme WS and Q were obtained using two types of field measurements. On the one hand, WS was measured manually in situ using a line gauge at the same time as the pressure probe and limnimeter recorded the WS. On the other hand, Q meterings using the float method or the area-velocity-method were carried out under a range of different magnitudes (see Table 2 and Annex), from low (baseflow) to high flows (flood events). All SDRCs obtained by DHN were based on a larger number of $\mathrm{Q}$ meterings (Fig. 3) performed from the center of the channel. However, these measurements were carried out from the river banks for high-Q conditions (i.e., WS $>1 \mathrm{~m}$ ) due the impossibility of measuring the flow velocity from the channel-center at M1 and M2 stations. 


\subsection{Stage-discharge rating curves elaboration}

The low and unrepresentative Q meterings carried out at AHN forced to the development of theoretic SDRCs based only on the specific hydraulic formulae of the gauging sections. Therefore, AHN SDRCs were derived theoretically based on Manning formulae (Limerinos, 1970) for the different WS levels.

The design of the low-flows channel coupled with the low gradient slope of the stream at L2 gauging station caused the impossibility to measure the flow velocity for WS levels $<0.50 \mathrm{~m}$ with the available OTT C31 current meter. Accordingly, some intervals of the SDRCs were elaborated by applying the Manning procedure (Limerinos, 1970) in these stations. The $n$ roughness coefficient was determined following Arcement and Schneider (1990) and the average stream gradient slope by using a topographic equipment (dGPS Leica 1200) along a longitudinal river section established $100 \mathrm{~m}$ up- and downstream of the gauging station. The WinXSPRO software (Hardy et al., 2005) was applied to analyse stream channel cross section data for geometric and hydraulic parameters. This software supports four alternative resistance equations for computing boundary roughness and resistance to flow. With the topographic channel cross sections and the determination of $n$ roughness coefficient, the WinXSPRo was applied to obtain Q values. It is worth to note that the Q meterings carried out during low-Q conditions were used to calibrate the Manning coefficient for the computation of the flow for the high-Q conditions, but taken into consideration the lower impact of the Manning coefficient on high flows, when the influence of the gauging structure is almost negligible. That issue could represent an additional source of uncertainty which could not be assessed on the present paper. Finally, it must be assumed that the equation is valid for these river sections under concrete weirs, despite changing conditions during flood events, as gauging sections were cleared regularly of debris and vegetation >100 m up- and downstream.

\subsection{Computation and data analysis}




\subsubsection{Water stage level}

WS levels obtained from DHN instruments (i.e. pressure probes) were calibrated with WS measurements carried out simultaneously during fieldwork to assess their functioning accuracy. WS levels measured by AHN could not be validated at any stations as the records which were provided by the Autonomous Government of the Balearic Islands never coincided on time with fieldwork; i.e., it was not possible to measure the real WS level at the same time when an AHN device was registering. Nevertheless, in the unique gauging station where a pressure probe (DHN) and a limnigraph (AHN) were simultaneously recording (i.e., M2), the WS levels obtained from DHN were compared with those obtained by AHN to assess their differences.

\subsubsection{Global uncertainty assessment}

Di Baldassarre and Montanari (2009) observed that the main sources of error affecting Q are the error in Q meterings (hereinafter $\varepsilon 1$ ); and the error due to SDRC uncertainty (hereinafter $\varepsilon 2$ ) which in turn is induced by its interpolation and extrapolation error, the presence of unsteady flow conditions, seasonal changes of roughness. These authors assumed that the global uncertainty can be obtained by:

$\varepsilon(\mathrm{Q}(\mathrm{x}, \mathrm{t}))= \pm \varepsilon 1(\mathrm{Q}(\mathrm{x}, \mathrm{t}))+\varepsilon 2(\mathrm{Q}(\mathrm{x}, \mathrm{t}))$

Traditional approaches are used in this study to infer $\varepsilon 1$, while original techniques are developed to evaluate the rating curve uncertainty $\varepsilon 2$. The latter is a difficult task as the methodology depends on the available information. In practical applications, the lack of information related with $\varepsilon 2$, led us to assess the SDRC uncertainty by using the deviation of the $\mathrm{Q}$ directly estimated from the $\mathrm{Q}$ meterings (hereinafter $Q_{g}$ ) from the predicted Q from the SDRCs (hereinafter $Q_{r c}$ ).

\section{- Uncertainty assessment of discharge meterings ( $\varepsilon 1)$}


The initial source of error results from the Q meterings. In order to quantify this uncertainty, the European ISO EN Rule 748 (1997) offers a methodology to quantify these errors at a 95\% confidence level:

$$
X^{\prime}{ }_{Q}= \pm \sqrt{X_{A}^{2}+\frac{1}{m}\left(X_{\theta}^{2}+X_{\varepsilon}^{2}+X_{B}^{2}+X_{d}^{2}+X_{p}^{2}\right)}
$$

where $X^{\prime}{ }_{Q}$ is the error of the $\mathrm{Q}$ metering $(\%) ; X_{b}$ is the uncertainty affecting the measurement of the crosssection width; $X_{d}$ is the uncertainty that affects to the WS measurement; $X_{e}$ is the uncertainty of the flow velocity related to the duration of the measurement; $X_{p}$ is the uncertainty of the flow velocity in function of the number of measurement points along each of the performed vertical sections, when at least 5 have been performed; $X_{c}$ is the uncertainty of the flow velocity associated with the calibration of the measuring instrument; and, $X_{A}$ is the uncertainty in the flow velocity depending on the number of vertical sections. Each singular uncertainty has been calculated by following the formulae stated by Herschy (1970).

\section{- Discharge uncertainty assessment in the stage-discharge rating curves ( $\varepsilon 2)$}

SDRC uncertainty is based in the concept that WS is uncertain through its own measurement errors. Tomkins (2014) analysed the SDRCs uncertainty in the Q values directly estimated from the Q meterings and their correspondence within the SDRCs. In this way, the relative deviation of the measurements (hereinafter D) from the corresponding SDRC was estimated to obtain the uncertainty between $\mathrm{Q}$ values:

$D=\left[\left(Q_{g}-Q_{r c}\right) / Q_{r c}\right] \times 100$

This relative $\mathrm{D}(\%)$ indicates the fitting degree between $\mathrm{Q}$ directly estimated from $\mathrm{Q}$ meterings and $\mathrm{Q}$ predicted from the SDRC for each single measurement. The results can be classified as good for $\mathrm{D}= \pm$ $10 \%$; acceptable $\pm 11-20 \%$; doubtful $\pm 21-50 \%$ and underestimated or over-estimated $\geq \pm 50 \%$ (Tomkins, 2014). At the M1 and M2 station, the AHN and DHN SDRCs were analysed using their respective Q metering. However, at the L1 and L2 station, this analysis was performed for both the AHN and DHN using only the Q meterings from the DHN, because no field measurements were carried out for the AHN. 


\subsubsection{Stage-discharge rating curves effects on hydrological dynamics}

Finally, SDRCs for AHN and DHN were applied and the resulting Q-series compared at the event and annual scales (i.e. 2007-08 hydrological year at L1 and L2 and 2013-14 hydrological year at M1 and M2) to assess the propagation of errors in the quantification of surface water resources. Selected parameters at the event scale were: $\mathrm{Q}_{\max }, \mathrm{Q}_{\text {average }}$ and event water yield $\left(\mathrm{E}_{\mathrm{wy}}, \mathrm{hm}^{3}\right)$, while at the annual scale, such parameter were: Qaverage and the annual water yield $\left(\mathrm{A}_{\mathrm{wy}}, \mathrm{hm}^{3}\right)$. Additionally, the uncertainty computed in previous section 2.4.2 was applied to calculate an associated Q (and related parameters) uncertainty band both at the event and annual scale.

\section{Results and Discussion}

\subsection{Calibration and comparison of water stage measurements}

A basic calibration and comparison of the instruments accuracy between AHN and DHN systems were initially performed. The comparison was only carried out at M2 station due that it is the only station where the contiguous installation of a limnigraph for AHN and a pressure probe for DHN allowed measuring WS simultaneously.

DHN-pressure probe at M2 was calibrated based on 15 in situ measurements of WS in a representative range (0 to $1.52 \mathrm{~m}$ ), therefore determining also the accuracy of the device (Fig. 4a). Likewise, in order to determine the uncertainty of the AHN records used in the historical data series at M2 station, 48 values of WS (from 0.00 to $1.03 \mathrm{~m}$ ) obtained simultaneously from the pressure probe and the limnigraph were compared (Fig. 4b), resulting a mean difference of $0.08 \pm 0.07 \mathrm{~m}$, being a $23 \%$ higher in AHN. This comparison revealed a worse functioning of the limnigraph, especially for low flow measurements, even observing that AHN measured WS values of $0.05 \mathrm{~m}$ (or higher) when the stream was actually dry (i.e., field observation) and the DHN-pressure probe was measuring (correctly) a WS of 0 (Fig. 4b). This error was 
very high if compared with the WS uncertainty review carried out by McMillan et al. (2012). Additionally, the instrumental precision in the vertical resolution of the WS $(0.01 \mathrm{~m}$ for the AHN and $0.0001 \mathrm{~m}$ for the DHN) inherently caused higher uncertainty in the Q computation of AHN records. According with Sauer and Turnipseed (2010), AHN main sources of uncertainty in WS are probably driven by some of the sources listed by such authors, so called: stage sensor errors related to the instrument performance, measurement conditions, water surface-to-sensor-to-recorder errors, mechanical problems, intake of the stilling well). Those errors have to be classified as systematic (i.e., generated by a sensor drift or inaccurate calibration) and should not be neglected at all (Horner et al., 2018).

\subsection{Global uncertainty assessment at the analogical and digital hydrometric networks}

The application of the procedure proposed by Di Baldassarre and Montanari (2009) estimated the total error as the sum of Q meterings $(\varepsilon 1)$ and SDRC $(\varepsilon 2)$ uncertainties, being their detailed results discussed as follows.

\subsubsection{Uncertainty assessment of discharge meterings $(\varepsilon 1)$}

At L1 and L2, the error of Q meterings from which the AHN SDRCs were elaborated could not be assessed as no Q metering was performed throughout the historical series. At M1 and M2, after applying the ISO EN Rule 748 (1997), the Q values obtained by AHN were based on a higher error than those obtained by DHN (Table 3). This fact can be attributed to the number of segments in which each gauging section was subdivided for the velocity measurements (i.e. only 2 to 4 in M1; 6 to 11 in the case of M2) because as higher is the number of segments across the gauging section, the more representative are the flow velocity data. Despite different measurement methods can increase an order-of-magnitude the transmission errors (Hamilton and Moore, 2012), the largest errors occurred using AHN in these two last stations were generated because the SDRC calibrations were not performed by means of Q meterings nor by the 
application of, for example, a Manning procedure for the $\mathrm{Q}$ estimation.

\subsubsection{Uncertainty assessment in the stage-discharge rating curves ( 22$)$}

The errors derived from the direct Q meterings were propagated towards the elaboration of the SDRCs. Therefore, the comparison of the deviations (D) analysis of those direct measurements $\left(\mathrm{Qg}_{\mathrm{g}}\right)$ with the predicted Q values ( $\mathrm{Q}_{\mathrm{rc}}$ ) in each SDRC (applying the method developed by Tomkins, 2014; see Annex for further details) showed larger differences in the D values derived from the AHN SDRCs at all the stations compared with the DHN SDRCs (Table 3).

The Tomkins (2014) method is simple to apply if compared to others (Reitan and Petersen-Overleir, 2008; Morlot et al., 2014). It basically makes no assumptions about the data or distributions, using the readily available meta-data more fully. It only requires a dataset of Q meterings not dependent on fitting a single mathematical function allowing a more accurate definition of the SDRC. Tomkins (2014), in a comparative study of historic SDRCs of 36 gauging stations in Australia, indicated that D between $\mathrm{Q}_{\mathrm{g}}$ and $\mathrm{Q}_{\mathrm{rc}} \geq \pm 50 \%$ should be classified as poor values. Accordingly, when the D values obtained for all the AHN and DHN SDRCs are analysed, it is clear that DHN performed generally better than AHN (Table 3). Then, the AHN SDRCs were constructed with only $16 \%$ of adjusted or acceptable deviations and $85 \%$ doubtful or overestimated. However, DHN SDRCs were elaborated with $65 \%$ of adjusted and acceptable (i.e., D $\leq$ $20 \%$ ) deviations and $34 \%$ doubtful, underestimated or overestimated ( $\geq 21 \%$ ). However, Tomkins (2014) method presents some weaknesses which also exist in other rating curve uncertainty approaches (McMillan et al., 2012) as can be: (1) a high degree of overfitting between nearest Q meterings; (2) a few number of Q meterings or located too distant between them can modify the curvature of the SDRC; (3) the residuals must be interpreted in the lower part of the SDRC because small differences in absolute values can be transformed in high deviations (which are not always meaning a worse SDRC); and, (4) the confidence 
limits can vary according the expertise of the scientist and the availability or difficulty to obtain Q meterings. Furthermore, the D value only allows to develop a single stationary uncertainty band in $\mathrm{Q}$ values while there are many other tools (e.g. BaRatin and $\underline{\text { HydraSub) }}$ which allow to compute and draw multiple flow uncertainty series (McMillan et al., 2017).

Finally, it should be noted that the opposite curvature of the SDRCs reflexed differences in the Q values at different WS, especially for their lower values, which represent another source of uncertainty. Such uncertainty for low WS and Q is related to the shape of the SDRC function and whether they fit or not from the origin of coordinates (i.e., 0,0 point). Then, the SDRCs which are not fitted tot that (i.e., M2, L1 and L2 from AHN and L1 from DHN) present residues in their equations and, consequently, zero values of WS do not produce zero values of $\mathrm{Q}$. Such values had to be adjusted to 0 manually.

\subsubsection{Global uncertainty calculation}

Lately, studies on hydrological uncertainties are mainly based on the evaluation of the SDRCs construction and development but they use ignoring the importance of WS or just assume that its related uncertainty is negligible. However, the relative contribution of WS to the global uncertainty depends on the degree of the SDRCs uncertainty and on the management of the hydrometric network (e.g., maintenance, sensor calibration). It has been proved that the uncertainties directly related with WS could increase up to $10 \%$ the SDRC uncertainty, especially in small catchments under ephemeral/intermittent regimes (Hornet et al., 2018), as it is the case of the present paper.

After applying the method developed by Di Baldassare and Montanari (2009), results reveal that the main source of errors lied in the SDRCs uncertainty ( 82 ; Table 3), even though AHN did not include the error of field measurements because not any single Q metering was carried out. It should be noted that D were 
higher using AHN's SQRCs than using DHN's, especially in L1 and L2, with just very few single values performing $\geq \pm 50 \%$ for DHN's at both sections, which could be considered as outliers (e.g., $105 \%$ in L1; see Annex) or generated due to the extremely low $Q$ values from which they were calculated (e.g., $\mathrm{Q}_{\mathrm{g}}=$ $0.009 \mathrm{~m}^{3} \mathrm{~s}^{-1}$ and $\mathrm{Q}_{\mathrm{rc}}=0.006 \mathrm{~m}^{3} \mathrm{~s}^{-1}$ in L2). However, higher D values do not always mean a worse SDRC elaboration. In the case of DHN, the largest total error (38\%) was observed in L2, mainly due to the inadequate construction design of the gauging section, which is located in a very flat section of the main stream (i.e., $0.0014 \%$ of slope). As a consequence, the DHN SDRC in L2 was partially built following the Manning approach, a method that presents an intrinsic uncertainty of $\pm 15 \%$ to $\pm 35 \%$ in the Q calculations (Slade, 2004).

Several authors have previously analysed and quantified the uncertainty for low Q, obtaining errors between $-43 \%$ to $73 \%$ (Westerberg et al., 2011), and between 50-100\% (McMillan et al., 2012), as well as for the intermediate and high flows, which was estimated in a range between 10-40\% (McMillan et al., 2012), and between $6.2 \%$ to $42.8 \%$ (Di Baldassare and Montanari, 2009). Moreover, McMillan et al. (2018) summarized the results obtained from the literature on hydrologic data uncertainty. They classified such studies, based on their coefficient of variation, into low (0-10\%) and medium (10-40\%) uncertainty, which places AHN (108\%) and DHN (25\%) within the very high and medium range respectively. Nevertheless, it must be stated that the $\mathrm{Q}$ values uncertainty in a gauging station can vary highly depending on the method which is applied (Kiang et al., 2018). These authors compared the SDRC uncertainties obtained from seven different methods at three river locations and they ranged for low flows between $28-101 \%$, for median between 3-17\% and for high flows between $41-200 \%$, so that must be taken into account when working with Q derived from SDRCs.

\subsection{Effects of the application of stage-discharge rating curves at analogical and digital hydrometric}


networks over hydrological dynamics

The hydrological effects of applying AHN and DHN SDRCs are here assessed comparing the SDRCs obtained from both hydrometric networks at event and annual scales.

\subsubsection{Event scale}

Figure 5 and Table 4 illustrate the derived Q dynamics at AHN and DHN for selected representative events of high and low magnitude at the gauging stations, excepting for M1, where the event scale could not be assessed due to the limnimeter's measuring frequency (i.e. daily).

In the case of M2, many differences are observed if AHN or DHN data are considered. For the seleceted high magnitude event (Fig. 5a), AHN recorded higher WS than DHN both at the beginning and at the end of the event. $\mathrm{Q}_{\max }$ was registered with a delay of 15 minutes in AHN, and WS decreased more sharply in the falling limb in DHN than in AHN. Q max $_{\text {ax }}$ and $\mathrm{E}_{\mathrm{wy}}$ were also higher in DHN than AHN. Oppositely, for the low magnitude event (Fig. 5b), the rising limb and $\mathrm{Q}_{\max }$ in AHN were delayed (i.e. 15 and 45 minutes respectively) compared to DHN, and WS decreased more sharply in DHN than in AHN. In addition, differences of up to one order of magnitude in $\mathrm{Q}_{\max }$ and $\mathrm{E}_{\mathrm{wy}}$ were observed (Table 4). In the case of $\mathrm{L} 1$, the high magnitude event (Fig. 5c) evidenced that $\mathrm{Q}_{\max }$ obtained by DHN was one order of magnitude higher than that obtained for AHN. Qaverage and $\mathrm{E}_{\mathrm{wy}}$ were very similar, presenting the smallest differences between both networks (Table 4). For the low magnitude event (Fig. 5d), Qmax, Qaverage and $E_{w y}$ obtained by DHN were three times lower than those of AHN. Finally the high magnitude event chosen at L2 (Fig. 5e) showed that $\mathrm{Q}_{\max }, \mathrm{Q}_{\text {average }}$ and $\mathrm{E}_{\mathrm{wy}}$ obtained by $\mathrm{AHN}$ were twice as high as those of DHN, while in the low magnitude (Fig. 5f), Q $\mathrm{max}_{\max }$, Qaverage and $\mathrm{E}_{\mathrm{wy}}$ obtained by AHN were three times higher than those of DHN.

As a result, the two events selected at M2 and the high magnitude one in L1 showed a clear underestimation 
of the Q values after the application of the AHN's SDRCs compared to the DHN's. Conversely, the low magnitude event in L1 and the two events in L2 presented an overestimation of the Q values of up to three times through the application of the AHN's SDRCs. Furthermore, the Q values obtained for the uncertainty bands and measured discharge reflected significant differences, ranging from 17 to $336 \%$ (Table 4), despite the drawn uncertainty bands do not overlap at M2 (Fig. 5a and 5b) and L1 (Fig. 5d), and presented a minimum overlap in L2 (Fig. 5f). Such values are even more remarkable when compared with the literature; Westerberg et al. (2011) found differences between two datasets ranging from -60 to $90 \%$ for low flows and $\pm 20 \%$ for medium and high flows.

\subsubsection{Annual scale}

Figure 6 performs the Q dynamics according to AHN and DHN SDRCs, whilst Qaverage and the annual water yield $\left(\mathrm{A}_{\mathrm{wy}}\right)$ were used for comparing relatively the results in the quantification of surface water resources at both hydrometric networks (Table 5). At M1, the differences of up to one order of magnitude (in favour of DHN) which were observed between $Q_{\max }, A_{w y}$ and $Q_{\text {average }}$ at the annual scale (Table 5) due to the different temporal resolution of the hydrometric networks, being daily in the case of AHN and 15-min for DHN. Thus, as AHN can only register daily values, it was impossible to accurately record a flood event because WS was recorded once per day reading a limnimeter at $8.00 \mathrm{~h}$ in the morning. Accordingly, more flood peaks were also recorded (Fig. 6a) when DHN was applied (i.e., 9 peaks, for only 5 peaks using AHN). Such differences were that large that the uncertainty boundaries of AHN and DHN do not overlap.

In M2, the $A_{w y}(2013 / 14)$ varied between $9.412 \mathrm{hm}^{3}$ following AHN and $15.587 \mathrm{hm}^{3}$ by using the DHN one. The main difference in the hydrographs (Fig. 6b) was again that observed for $\mathrm{Q}_{\max }$, which was three times larger for DHN compared to AHN (Table 5). Furthermore, the application of AHN generated longer recessions and a wrong continuous record of baseflow from December to May, as WS levels higher than 0 
were systematically registered despite that the stream was mostly dry during the whole period. Such sources of uncertainty are associated to the malfunctioning of the AHN recording system (Fig. 4b) and to the presence of residues in the SDRC equation (Fig. 3c). However, despite AHN and DHN uncertainties overlapped in simultaneous peaks, AHN recessions presented larger uncertainties than DHN.

The $A_{w y}(2007 / 08)$ at $\mathrm{L} 1$ was double in AHN than DHN (Table 5). The $\mathrm{Q}_{\max }$ during events was very different too, ranging from 1.350 to $6.910 \mathrm{~m}^{3} \mathrm{~s}^{-1}$ in $\mathrm{L} 1 \mathrm{AHN}$ and from 0.507 to $11.332 \mathrm{~m}^{3} \mathrm{~s}^{-1}$ in L1 DHN (Fig. 6c). These differences in $\mathrm{Q}_{\max }$ peaks increased were uncertainy bands were applied, special in low to intermediate $Q$ values, Uncertainties overlapped in Q values higher than $2 \mathrm{~m}^{3} \mathrm{~s}^{-1}$.

At the L2 station, the inadequate design of the low-waters channel in a cross-section of the stream with a very gentle slope $(0.014 \%)$ caused a wrong transformation of WS to $Q$ throughout the flow range. Therefore, Q was largely overestimated for the AHN SDRC for all WS as it is reflected in the annual $\mathrm{Q}_{\max }$, $\mathrm{A}_{\mathrm{wy}}$ and also in the Qaverage (Table 5). The AHN uncertainty in Q values was reflected in all the WS range (Fig. 6d). For DHN stations, L2 presented presetend the highest uncertainty. Nevertheless, DHN procedure in meterings and SDRC elaboration allowed to reduce the uncertainty compared to AHN. The difference between $\mathrm{AHN}$ and $\mathrm{DHN}$ in the $\mathrm{Q}_{\max }$ during events was the highest of all stations, with relative differences ca. $>200 \%$.

\section{Conclusions}

The analysis of Q meterings and SDRCs deviations carried out at the present paper has been proved as a valid method for the assessment of the reliability of the data obtained from two independent hydrometric networks (i.e., AHN and DHN) with different data collection and recording systems, time series, maintenance and SDRCs management. Results allowed the discrimination of the stations presenting the 
largest monitoring limitations, evidencing that AHN is way more problematic and limited than DHN. In addition, the analysis of the $\mathrm{Q}$ data registered for both hydrometric networks at different time scales (i.e., event and annual scales) has evidenced (and evaluated) the propagation of errors of such data from the field measurements to the final computations of the annual contribution. Those errors have showed differences of up to two orders of magnitude between the $\mathrm{Q}$ values measured for each hydrological network. Nevertheless, such values have been used anyway for decades for the quantification of the surface water resources in the Balearic Islands, as well as for hydrological and flooding-hazards prevention, planning, management and modelling.

The main source of uncertainty has been identified as that derived from the construction of SDRCs. The relative contribution of this to the general uncertainty ranged from 68 to $94 \%$ in $\mathrm{AHN}$ and from 72 to $87 \%$ in DHN. Q meterings general uncertainty had a relative contribution lower than $20 \%$. Nevertheless, that contribution increased up to $32 \%$ in AHN due to the generally wrong procedure in the Q meterings. Furthermore, the assessment of the performance of AHN (i.e. implemented over 40 years) and DHN (i.e. 10 years of implementation) regarding total water yields resulted in a propagation of errors with contrasted and remarkable consequences for the quantification of the surface water resources in Mallorca. The impact was evaluated at each station and resulted in an average difference in water yield values of up to $183 \%$ at the event time scale and $142 \%$ at the annual scale, which represents an under/overerestimation up to 6 and $22 \mathrm{hm}^{3}$ respectively in the annual water yield. Such differences represent a third part of the historic AHN average value (underestimation scenario) or even larger than the major annual water yield contribution registered by AHN (overestimation scenario).

The differences between recording systems (especially in the case of M1) have been proved to be decisive in the provision of WS values, which are essential for a reliable computation of hydrological processes in 
catchments characterised hydrologically by flash-floods (Gallart et al. 2008), as it is exactly the case of Sant Miquel and Na Borges catchments. Consequently, having an accurately measured WS record is essential for a proper estimation of the water resources, making practically impossible to amend historical records which were wrongly gauged (e.g. WS measured historically at AHN cannot be amended afterwards thus the proper rating curves created for DHN could not be either applied for a better estimation of the water resources).

It is well known that a poor maintenance of recording systems without a systematic field calibration for an optimum management of SDRCs leads to a lack of representativeness and validity of the data and, hence, to a loss of continuity of correct data in the historical series. Then, it is clear that fieldwork procedures for obtaining water stage and Q meterings are required as a non-stop maintenance of the digital system. If those procedures are not carried out, the recorded values will be never valid even if they have been obtained by means of a continuous hydrological process monitoring. Furthermore, computing streamflow uncertainties can reduce project costs and improve stakeholders' decisions (McMillan et al., 2018), so studies like the aforementioned (no matter if they have been carried out at global or regional scales) are needed and essential. Such studies provide clues to improve the planning and management of the scarce water resources (and flood hazards) in the Mediterranean, and particularly in an island, where these resources are eco-sociologically crucial (Kent et al. 2002) especially under the current global change context.

\section{Acknowledgments}

This work was supported by a research contract funded in 2014 by the Directorate-General of Water Resources (Department of Environment, Agriculture, and Fishery of the Balearic Autonomous Government) and the research project CGL2012-32446 "Assessing hydrological and sediment connectivity in contrasting 
Mediterranean catchments. Impacts of Global Change-MEDhyCON" funded by the Ministry of Economy and Competitiveness of the Spanish Government. The contribution of Jérôme Latron was supported by the research project PCIN-2017-061/AEI also funded by the Ministry of Economy and Competitiveness of the Spanish Government. Josep Fortesa has a contract funded by Ministry of Innovation, Research and Tourism of the Autonomous Government of the Balearic Islands (FPI/2048/2017). He also acknowledges the support from "la Caixa" Foundation through a mobility grant for young researchers at the Universitat de les Illes Balears with announcement reference number 3111. Julián García-Comendador is in receipt of a predoctoral contract (FPU15/05239) funded by the Spanish Ministry of Education and Culture. Aleix Calsamiglia acknowledges the support from the Spanish Ministry of Economy and Competitiveness through a pre-doctoral contract (BES-2013-062887). José Andrés López-Tarazón is in receipt of a Vicenç Mut postdoctoral fellowship (CAIB PD/038/2016) funded by the Vice-presidency and Ministry of Innovation, Research and Tourism of the Autonomous Government of the Balearic Islands. Meteorological data were facilitated by the Spanish Meteorological Agency (AEMET).

\section{References}

Arcement, G.J. and Schneider, V.R., 1990. Guide for Selecting Manning's Roughness Coefficients for Natural Channels and Flood Plains. Water-Supply Paper 2339, U.S. Geological Survey, Washington, DC.

Borga, M., Anagnoustou, E.N., Blöschl, G., Creutin, J.D., 2010. Flash floods: observations and analysis of hydro-meteorological controls. J. Hydrol. 394:1-3. doi:10.1016/j.jhydrol.2010.07.048

Bayazit, M. 2015. Nonstationarity of Hydrological Records and Recent Trends in Trend Analysis: A Stateof-the-art Review. Environ. Proc. 2: 527-542. DOI: 10.1007/s40710-015-0081-7

Di Baldassarre, G., Montanari, A., 2009. Uncertainty in river discharge observations: a quantitative analysis. 
Estrany, J., 2008. Calibratge de la corba d'aforaments i anàlisi de resultats a estacions d'aforament experimentals. Technical report. Direcció General de Recursos Hídrics. Conselleria de Medi Ambient. Govern de les Illes Balears.

Estrany, J., 2009. Hydrology and sediment transport in the agricultural Na Borges River basin (Mallorca, Balearic Islands). A Mediterranean groundwater-dominated river under traditional soil conservation practices. Unpublished PhD thesis. Palma, Universitat de les Illes Balears.

Estrany, J., Grimalt, M., 2014. Catchment controls and human disturbances on the geomorphology of small Mediterranean estuarine systems. Estuar. Coast. Shelf Sci. 150, 230-241. https://doi.org/10.1016/j.ecss.2014.03.021

European ISO EN Rule 748., 1997. Measurement of liquid flow in open channels - velocity-area methods, Reference number ISO748:1997 (E), International Standard.

Gallart, F., Amaxidis, Y., Botti, P., Canè, G., Castillo, V., Chapman, P., Froebrich, J., Garcíapintado, J., Latron, J., Llorens, P., Lo Porto, A., Morais, M., Neves, R., Ninov, P., Perrin, J.L., Ribarova, I., Skoulikidis, N., Tournoud, M.G., 2008. Investigating hydrological regimes and processes in a set of catchments with temporary waters in Mediterranean Europe. Hydrol. Sci. J. 53(3), 618-628. https://doi.org/10.1623/hysj.53.3.618

García-Ruiz, J. M., López-Moreno, J. I., Vicente-Serrano, S. M., Lasanta-Martínez, T., Beguería, S., 2011. Mediterranean water resources in a global change scenario. Earth-Sci. Rev. 105(3-4), 121-139. https://doi.org/10.1016/j.earscirev.2011.01.006

Guerrero, J. L., Westerberg, I. K., Halldin, S., Xu, C. Y., Lundin, L. C., 2012. Temporal variability in stage-discharge relationships. J. Hydrol. 446, 90-102. https://doi.org/10.1016/j.jhydrol.2012.04.031 
506 Gravelle, R., 2015. Discharge Estimation: Techniques and Equipment. Geomorphological Techniques,

507

Chap. 3, Sec.3.5. British Society for Geomorphology. ISSN 2047-0371.

Hamilton, A. S., Moore, R. D., 2012. Quantifying uncertainty in streamflow records. Can. Water Resour. J. 37 (1), 3-21. https://doi.org/10.4296/cwrj3701865

Herschy, R. W.: Accuracy in Hydrometry, edited by: Herschy, R. W., Wiley, New York, NY, USA, 353$397,1978$.

Jenkins, H. C., Sellwood, B. W., Pomar, L. 1990. A Field Excursion Guide to the Island of Mallorca. (C. J. Lister, Ed.)Geologists’ Association Guides. London: The Geologist's Association.

Kent, M., Newnham, R. and Essex, S., 2002. Tourism and sustainable water supply in Mallorca: a geographical analysis. App. Geogr. 22 (4), 351-374. https://doi.org/10.1016/S0143-6228(02)00050-4.

Le Coz, J., 2008. Challenges in hydrometry: some examples from France. Experiences and Advancements in Hydrometry. Mar 2008, Seoul, South Korea. 8 p. https://hal.archives-ouvertes.fr/hal-00509246.

Le Coz, J., Renard, B., Bonnifait, L., Branger, F., \& Le Boursicaud, R. 2014. Combining hydraulic knowledge and uncertain gaugings in the estimation of hydrometric rating curves: A Bayesian approach. J. Hydrol. 509, 573-587. https://doi.org/10.1016/j.jhydrol.2013.11.016.

Limerinos, JT. 1970. Determination of the Manning Coefficient from Measured Bed Roughness in Natural Channels. Water Supply Paper 1898B, U.S. Geological Survey, Washington, DC.

McMillan, H., Krueger, T. and Freer, J., 2012. Benchmarking observational uncertainties for hydrology: rainfall, river discharge and water quality. Hydrol. Process. 26, 4078-4111. https://doi.org/10.1002/hyp.9384 
McMillan, H. K., and I. K. Westerberg. 2015. Rating curve estimation under epistemic uncertainty. Hydrol. Process. 29 (7) 1873-1882. https://doi.org/10.1002/hyp.10419Mishra, A. K. and Coulibaly, P., 2009. Developments in hydrometric network design: A review. Rev. Geophys. 47. https://doi.org/10.1029/2007RG000243

Morlot, T., Perret, C., Favre, A. C. and Jalbert, J. 2014. Dynamic rating curve assessment for hydrometric stations and computation of the associated uncertainties: Quality and station management indicators. J. Hydrol. 517, 173-186. https://doi.org/10.1016/j.jhydrol.2014.05.007.

Pappenberger, F. et al., 2006. Influence of uncertain boundary conditions and model structure on flood inundation predictions. Adv. Water Resour. 29(10), 1430-1449.

Pardo I. and Olsen A.M., 2004. Tipologías A y B de los torrentes de las islas Baleares. Technical report. Direcció General de Recursos Hídrics. Conselleria de Medi Ambient. Directiva Marco del agua en las islas Baleares.

Pelletier, M. P., 1987. Uncertainties in the determination of river discharge: a literature review, Can. J. Civil Eng. 15, 834-850. https://doi.org/10.1139/188-109

Petersen-Øverleir, A., Soot, A. and Reitan, T., 2009. Bayesian rating curve inference as a streamflow data quality assessment tool. Water Resour. Manag. 23(9), 1835-1842. https://doi.org/10.1007/s11269-008-93545

Rantz S.E., 1982. Measurement and Computation of Streamflow: Volume 2. Computation of Discharge. Water Supply Paper 2175, U.S. Geological Survey, Washington, DC.

Reitan, T. and Petersen-Øverleir, A. 2008. Bayesian power-law regression with a location parameter, with applications for construction of discharge rating curves. Stoc. Environ. Res. Risk Assess. 22(3), 351-365. https://doi.org/10.1007/s00477-007-0119-0. 
Reitan, T., \& Petersen-Øverleir, A. 2011. Dynamic rating curve assessment in unstable rivers using Ornstein-Uhlenbeck processes. Water Resour. Res. 47(2). doi:10.1029/2010WR009504.

Shannon, J. U. L. I. E., Richardson, R., Thornes, J. O. H. N., 2002. Modelling event-based fluxes in ephemeral streams. John Wiley \& Sons. United Kingdom: Chichester.

Shaw, E.M., 1994. Hydrology in Practice, Third Ed.. Chapman \& Hall, London. ISBN 13: 978-0-415$37041-7$.

Slade, R. M., 2004. General methods, information, and sources for collecting and analyzing water-resources data. [CD-ROM. Copyright.]

Tomkins, K. M., 2014. Uncertainty in streamflow rating curves: methods, controls and consequences. Hydrol. Process. 28(3), 464-481. https://doi.org/10.1002/hyp.9567

Hardy, T., Panja, P., Mathias, D., 2005. WinXSPRO, A Channel Cross Section Analyzer, User's Manual, Version 3.0. United States Department of Agriculture. General Technical Report RMRS-GTR-147.

Volkmann, T. H., Lyon, S. W., Gupta, H. V., Troch, P. A. 2010. Multicriteria design of rain gauge networks for flash flood prediction in semiarid catchments with complex terrain. Water resources research. 46, 1-16. https://doi.org/ 10.1029/2010WR009145

Yu, B. 2000. A systematic over-estimation of flows. J. Hydrol. 233(1-4), 258-262. .

Ward, A. R. C., 1967. Design of Catchment Experiments for Hydrological Studies. Published by: The Royal Geographical Society (with the Institute of British Geographers). The Geographical Journal. 133(4), 495-502. https://doi.org/10.2307/1794478 
567 Westerberg, I., Guerrero, J. L., Seibert, J., Beven, K. J., Halldin, S. 2011. Stage-discharge uncertainty 568 derived with a non-stationary rating curve in the Choluteca River, Honduras. Hydrol. Process. 25(4), 603569 613. https://doi.org/10.1002/hyp.7848 
Figures captions.

Fig. 1. Methodological workflow of the research study.

Fig. 2. Map of the Mallorca Island representing the analogic (AHN) and digital (DHN) hydrometric networks as well as the location of the Sant Miquel and $\mathrm{Na}$ Borges basins within the fluvial network of the island. Left set map represents the location of Mallorca in the Western Mediterranean Sea. Bottom and right set figures are upstream views of the selected gauging stations.

Fig. 3. Stage-discharge rating curves at M1 - Comafreda for (a) AHN and (b) DHN; atM2 Sant Miquel for (c) AHN and (d) DHN; at L1 - Sa Vall for (e) AHN and (f) DHN; and at L2 Ses Pastores for (g) AHN and (h) DHN. MP are Measured Points; TP are Theoretic Points; LMP are Low/intermediate Q measured points; LTP are Low/intermediate theoretic points; HMP are Intermediate/high Q measured points and HTP are Intermediate/high theoretic points.

Fig. 4. Accuracy assessment of instruments at M2 - SantMiquel gauging station: (a) calibration of digital records collected by a pressure probe with in situ fieldmeasurements of theWS and (b) comparison of analogic records collected by a limnigraph with digital records.

Fig. 5. Application of stage-discharge rating curves forAHNand DHNthrough hydrographs in high and lowmagnitude events at (a and b)M2- SantMiquel, (c and d) L1 - Sa Vall and (e and f) L2 - Ses Pastores gauging stations. The Q uncertainty band is also plotted in each of the hydrographs.

Fig. 6. Annual hydrograph for the (a)M1 - Comafreda, (b) M2- Sant Miquel, (c) L1 - Sa Vall and (d) L2 - Ses Pastores gauging stations according to each SDRC elaborated for AHN and DHN. The Q uncertainty band is also plotted in each of the hydrographs. 
2.2 Monitoring systems and validation Validation from AHN and DHN stations in the same gauging site

2.3 Stage-discharge rating curves -SDRCs elaboration

\subsection{Computation and data analysis}

$\begin{gathered}\text { 2.2.1 Selected gauging stations } \\ \text { Four stations from } 2 \text { contrasted } \\ \text { catchments shared by AHN and DHN }\end{gathered}$
M1 - Mountainous station 1
M2 - Mountainous station 2
L2 - Lowland station 1

AHN

Theoretic SDRC's

DHN $\begin{gathered}\text { Combaining experimental and Manning } \\ \text { formulae to obtain SDRC }\end{gathered}$

\subsubsection{Water stage level}

\subsubsection{Gobal uncertainty assessment}

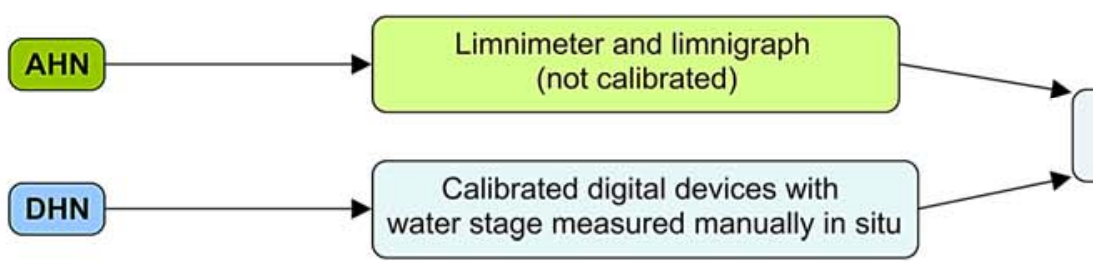

Functioning comparison of both recording systems

Uncertainty of
Q metering's $(\varepsilon 1)$

Applying the global uncertainty computation at event and annual scales: band of uncertainty in $Q$ values
Slobal uncertainty computation by suming $\varepsilon 1$ and $\varepsilon 2$ 


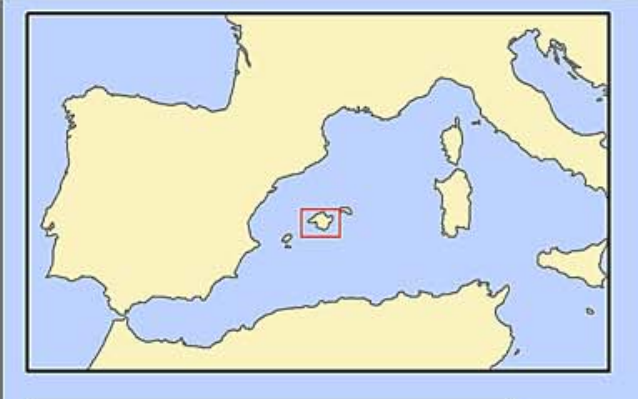

- AHN station

- $\mathrm{AHN}$ - DHN coincidence station

- DHN station

- Fluvial network

$\square$ Mountainous Sant Miquel catchment

$\square$ Lowland $\mathrm{Na}$ Borges catchment

\section{Elevation (m)}

\begin{tabular}{|c|c|c|}
\hline . & | $0-50$ & $350-700$ \\
\hline & $50-200$ & $700-1,000$ \\
\hline & $200-350$ & $1,000-1,445$ \\
\hline
\end{tabular}

$\hat{\Lambda}$

$10 \quad 20 \mathrm{~km}$

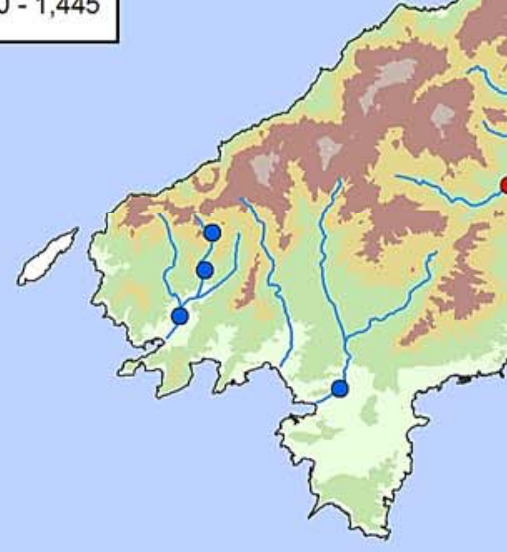

0
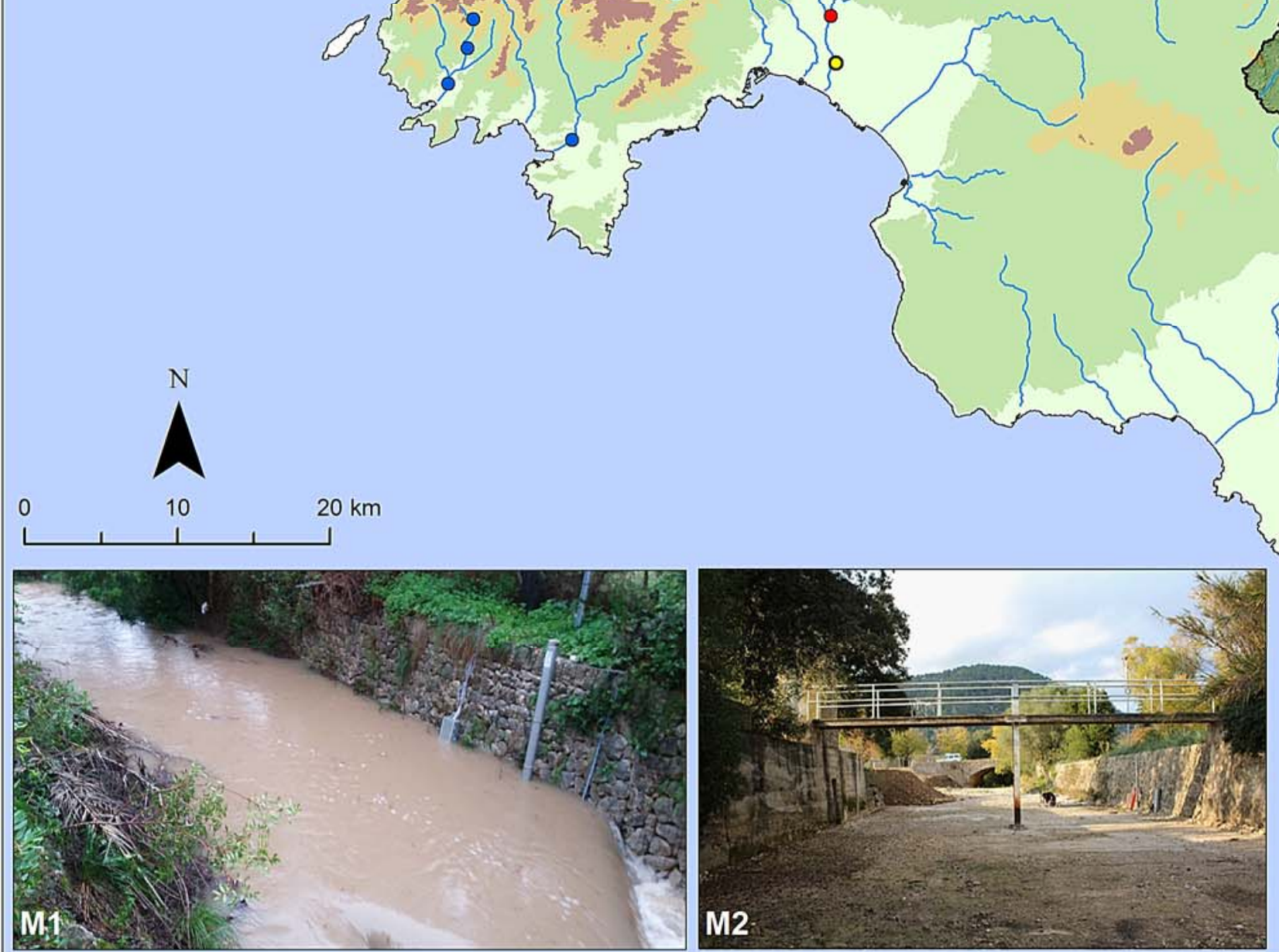

M1 and M2

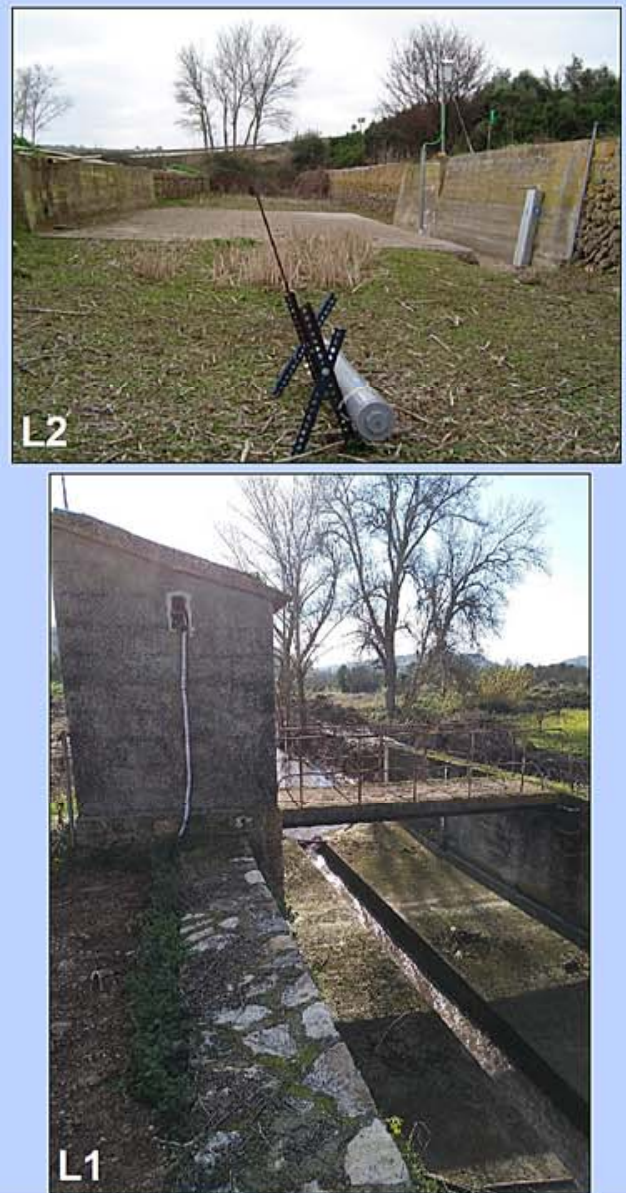




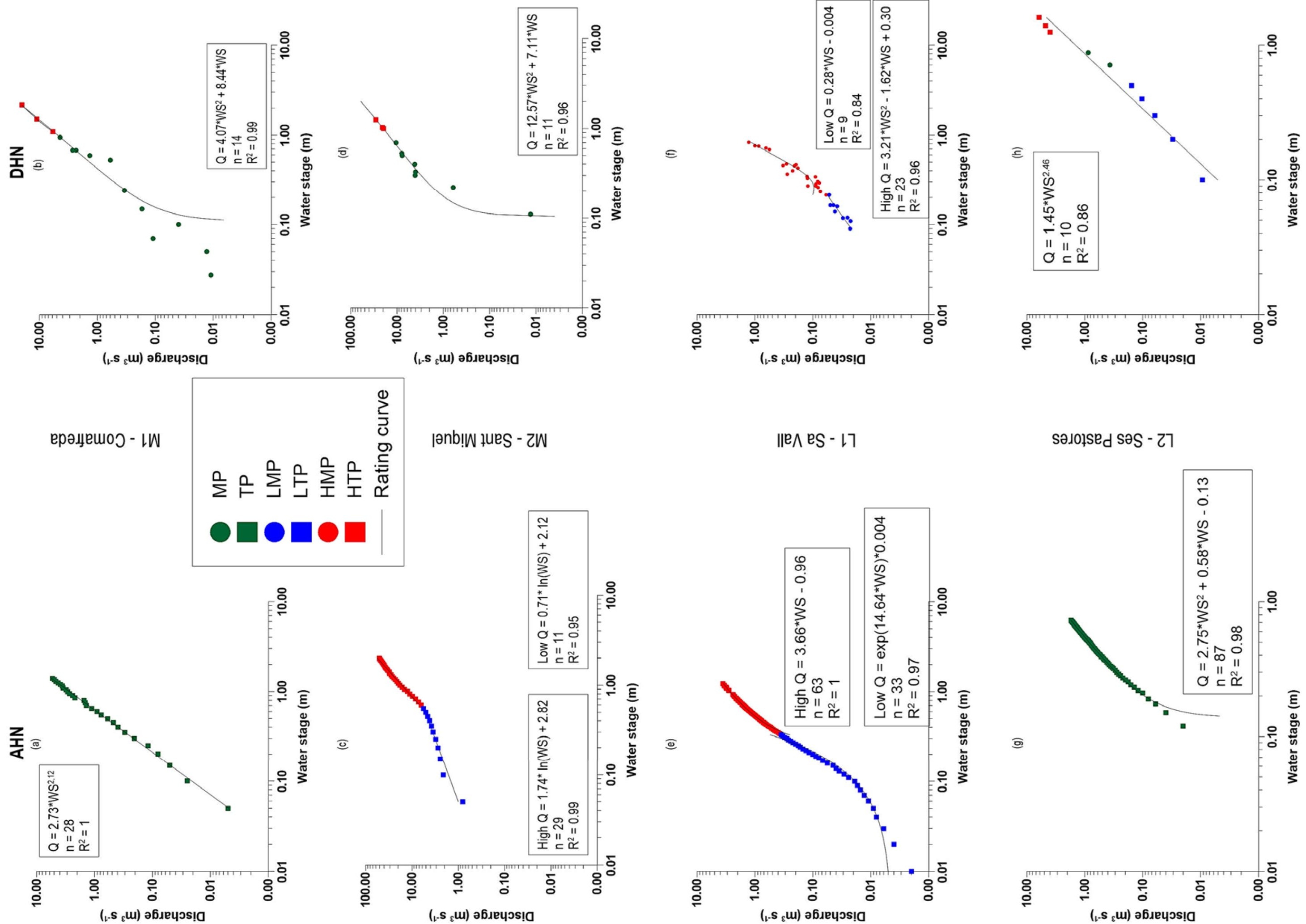




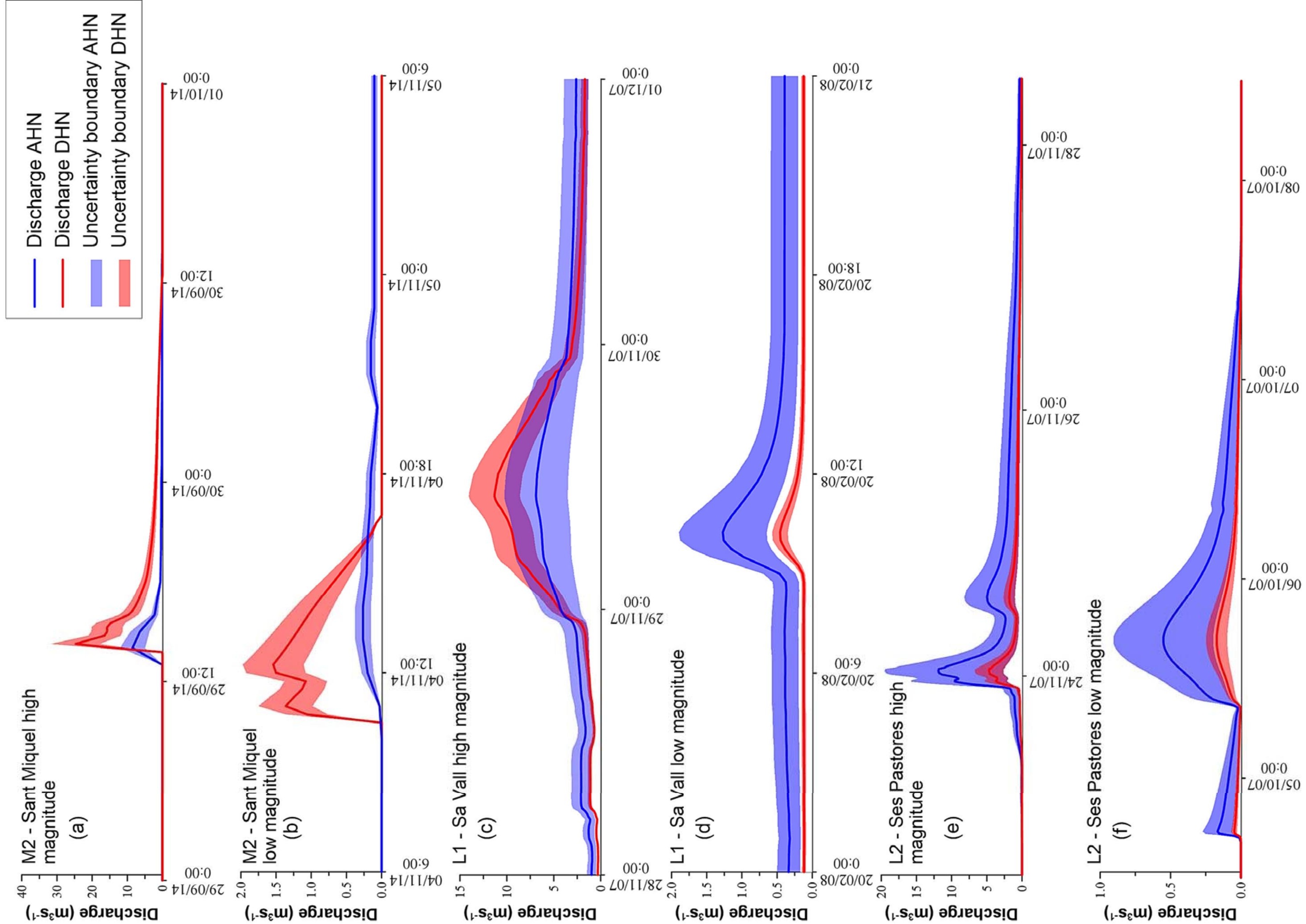


Table 1. Main characteristics of selected catchments as well as average runoff and type of recording systems at gauging stations.

\begin{tabular}{|c|c|c|c|c|c|c|}
\hline Catchment & Precipitation & Land uses & Gauging station & Average annual runoff (AHN) & Recording systems & Weirs types \\
\hline \multirow{2}{*}{$\begin{array}{l}\text { Mountainous } \\
\text { Sant Miquel } \\
152 \mathrm{~km}^{2}\end{array}$} & \multirow{2}{*}{$\begin{array}{c}1,262 \mathrm{~mm} \\
(1993-2011, \\
\text { Lluc AEMET } \\
\text { station) }\end{array}$} & \multirow{2}{*}{$\begin{array}{l}\text { Forest and } \\
\text { agricultural }\end{array}$} & $\begin{array}{l}\text { M1 - Comafreda } \\
31 \mathrm{~km}^{2}\end{array}$ & $48 \mathrm{~mm} \pm 144 \%(1977-2015)$ & $\begin{array}{l}\text { AHN: Limnimeter } \\
\text { DHN: Water height probe }\end{array}$ & $\begin{array}{l}\text { Rectangular broad-crested at } \\
\text { low and high-flow channels }\end{array}$ \\
\hline & & & $\begin{array}{l}\text { M2 - Sant Miquel } \\
52 \mathrm{~km}^{2}\end{array}$ & $373 \mathrm{~mm} \pm 81 \%(1968-2015)$ & $\begin{array}{l}\text { AHN: Limnimeter } \\
\text { DHN: Water height probe }\end{array}$ & Rectangular broad-crested \\
\hline \multirow{2}{*}{$\begin{array}{l}\text { Lowland } \\
\text { Na Borges } \\
320 \mathrm{~km}^{2}\end{array}$} & \multirow{2}{*}{$\begin{array}{c}572 \mathrm{~mm} \\
(1974-2006, \\
\text { Boscana Nou } \\
\text { AEMET } \\
\text { station) }\end{array}$} & \multirow{2}{*}{ Agricultural } & $\begin{array}{l}\mathrm{L} 1-\mathrm{Sa} \text { Vall } \\
264 \mathrm{~km}^{2}\end{array}$ & $157 \mathrm{~mm} \pm 89 \%$ (1971-2009) & $\begin{array}{l}\text { AHN: Limnimeter } \\
\text { DHN: Water height probe }\end{array}$ & \multirow{2}{*}{$\begin{array}{l}\text { Rectangular broad-crested a } \\
\text { low and high-flow channels }\end{array}$} \\
\hline & & & $\begin{array}{l}\text { L2 - Ses Pastores } \\
316 \mathrm{~km}^{2}\end{array}$ & $4 \mathrm{~mm} \pm 177 \%(1976-2015)$ & $\begin{array}{l}\text { AHN: Limnimeter } \\
\text { DHN: Water height probe }\end{array}$ & \\
\hline
\end{tabular}


Table 2. Number and type of metering's, instruments and stage-discharge rating curves characteristics at each gauging station.

\begin{tabular}{|c|c|c|c|c|c|c|c|c|c|c|c|}
\hline $\begin{array}{l}\text { Gauging } \\
\text { station }\end{array}$ & SDRC & $\begin{array}{l}\text { Readings } \\
\text { and WS } \\
\text { range }(\mathbf{m})\end{array}$ & $\begin{array}{l}\text { Q } \\
\text { metering's } \\
\text { and WS } \\
\text { range }(\mathbf{m})\end{array}$ & $\begin{array}{l}\text { Sampling } \\
\text { frequency }\end{array}$ & $\begin{array}{l}\text { Type of Q } \\
\text { metering's }\end{array}$ & $\begin{array}{l}\text { Instrument, velocity measurement range } \\
\text { and accuracy for } Q \text { metering's }\end{array}$ & SDRC type & $\begin{array}{l}\text { SDRC } \\
\text { segments }\end{array}$ & Equation & $\begin{array}{c}n \\
\text { Manning }\end{array}$ & Slope \\
\hline \multirow{2}{*}{$\begin{array}{c}\text { M1 - } \\
\text { Comafreda }\end{array}$} & AHN & 0 & $\begin{array}{r}5(0.07-0.38 \\
\mathrm{m})\end{array}$ & $\begin{array}{r}\text { Current } \\
\text { measurements } \\
\text { since 1960s }\end{array}$ & Float method & -- & Theoretic & 1 & $\begin{array}{r}\text { Power } \\
\text { regression }\end{array}$ & - & - \\
\hline & DHN & $\begin{array}{r}11(0.00- \\
0.70 \mathrm{~m})\end{array}$ & $\begin{array}{r}14(0.04- \\
2.15 \mathrm{~m})\end{array}$ & $\begin{array}{r}\text { Every } 2 \\
\text { months and } \\
\text { during flood } \\
\text { events }\end{array}$ & $\begin{array}{l}\text { Area-velocity- } \\
\text { method }\end{array}$ & $\begin{array}{r}\text { OTT MF PRO [0 to } 6.09 \mathrm{~m} \mathrm{~s}^{-1} \text { accuracy of } 2 \% \\
\left(0 \text { to } 3 \mathrm{~m} \mathrm{~s}^{-1}\right) \text { and } 4 \%\left(3 \text { to } 5 \mathrm{~m} \mathrm{~s}^{-1}\right) \text { for measured } \\
\text { values } \pm 0.015 \mathrm{~m} \mathrm{~s}^{-1} \text { (SD)] }\end{array}$ & $\begin{array}{l}\text { Experimental and } \\
\text { Manning } \\
\text { formulae for high } \\
\text { Q }\end{array}$ & 1 & Polynomic & 0.060 & $1.28 \cdot 10^{-2}$ \\
\hline \multirow{2}{*}{$\begin{array}{l}\text { M2 - Sant } \\
\text { Miquel }\end{array}$} & AHN & 0 & $\begin{array}{r}6(0.20-0.90 \\
\mathrm{m})\end{array}$ & $\begin{array}{r}\text { Current } \\
\text { measurements } \\
\text { since } 1960 \mathrm{~s}\end{array}$ & $\begin{array}{l}\text { Area-velocity- } \\
\text { method }\end{array}$ & OTT C31 (0.025 to $10 \mathrm{~m} \mathrm{~s}^{-1}$ accuracy of $\left.2 \%\right)$ & Theoretic & $\begin{array}{c}2(0.05- \\
0.55 \mathrm{~m} / / \\
0.55-2.00 \\
\mathrm{~m})\end{array}$ & Exponential & - & - \\
\hline & DHN & $\begin{array}{r}12(0.00- \\
1.52 \mathrm{~m})\end{array}$ & $\begin{array}{r}11(0.11- \\
1.25 \mathrm{~m})\end{array}$ & $\begin{array}{r}\text { Every } 2 \\
\text { months and } \\
\text { during flood } \\
\text { events } \\
\end{array}$ & $\begin{array}{r}\text { Area-velocity- } \\
\text { method }\end{array}$ & $\begin{array}{r}\text { OTT MF PRO [0 to } 6.09 \mathrm{~m} \mathrm{~s}^{-1} \text { accuracy of } 2 \% \\
\left(0 \text { to } 3 \mathrm{~m} \mathrm{~s}^{-1}\right) \text { and } 4 \%\left(3 \text { to } 5 \mathrm{~m} \mathrm{~s}^{-1}\right) \text { for measured } \\
\text { values } \pm 0.015 \mathrm{~m} \mathrm{~s}^{-1} \text { (SD)] }\end{array}$ & $\begin{array}{l}\text { Experimental and } \\
\text { Manning } \\
\text { formulae for high } \\
\text { Q }\end{array}$ & 1 & Polynomic & 0.065 & $1.55 \cdot 10^{-2}$ \\
\hline \multirow{3}{*}{$\begin{array}{c}\mathrm{L} 1-\mathrm{Sa} \\
\text { Vall }\end{array}$} & AHN & 0 & 0 & $\begin{array}{r}\text { Without } \\
\text { measurements }\end{array}$ & -- & -- & Theoretic & $\begin{array}{c}2(0.00- \\
0.33 \mathrm{~m} / / \\
0.33-1.22\end{array}$ & $\begin{array}{r}\text { Exponential } \\
\text { and lineal }\end{array}$ & - & - \\
\hline & & & & & & & & m) $\ldots$ & & & \\
\hline & DHN & $\begin{array}{r}67(0.00- \\
0.90 \mathrm{~m})\end{array}$ & $\begin{array}{r}32(0.09- \\
0.83 \mathrm{~m})\end{array}$ & $\begin{array}{r}\text { Every } 2 \\
\text { months and } \\
\text { during flood } \\
\text { events }\end{array}$ & $\begin{array}{r}\text { Area-velocity- } \\
\text { method }\end{array}$ & OTT C31 ( 0.025 to $10 \mathrm{~m} \mathrm{~s}^{-1}$ accuracy of $\left.2 \%\right)$ & Experimental & $\begin{array}{c}2(0.00- \\
0.21 \mathrm{~m} / / \\
0.21-2.50 \\
\mathrm{~m})\end{array}$ & $\begin{array}{r}\text { Polynomic } \\
\text { and lineal }\end{array}$ & - & - \\
\hline \multirow[b]{2}{*}{$\begin{array}{l}\text { L2 - Ses } \\
\text { Pastores }\end{array}$} & AHN & 0 & 0 & $\begin{array}{r}\text { Without } \\
\text { measurements }\end{array}$ & -- & -- & Theoretic & 1 & Polynomic & - & - \\
\hline & DHN & 0 & $\begin{array}{r}5(0.50-1.60 \\
\mathrm{m})\end{array}$ & $\begin{array}{r}\text { Every } 2 \\
\text { months and } \\
\text { during flood } \\
\text { events }\end{array}$ & $\begin{array}{r}\text { Area-velocity- } \\
\text { method }\end{array}$ & OTT C31 (0.025 to $10 \mathrm{~m} \mathrm{~s}^{-1}$ accuracy of $\left.2 \%\right)$ & $\begin{array}{l}\text { Experimental and } \\
\text { Manning } \\
\text { formulae for high } \\
\text { Q }\end{array}$ & 1 & Potential & 0.029 & $1.42 \cdot 10^{-4}$ \\
\hline
\end{tabular}


1 Table 3. Proportion of gauges and its category classification and the global uncertainty components such as 2 Q metering's ( $\varepsilon 1)$ and error due to stage-discharge rating curve uncertainty ( $\varepsilon 2)$ for AHN and DHN at M1 3 Comafreda, M2 - Sant Miquel, L1 - Sa Vall and L2 - Ses Pastores stations.

\begin{tabular}{|c|c|c|c|c|c|c|c|c|c|c|c|}
\hline \multirow[t]{2}{*}{ Category } & \multirow{2}{*}{$\begin{array}{c}\text { Percentage } \\
\text { of } \\
\text { deviation }\end{array}$} & \multicolumn{2}{|c|}{$\begin{array}{c}\text { M1 - } \\
\text { Comafreda }\end{array}$} & \multicolumn{2}{|c|}{$\begin{array}{c}\text { M2 - Sant } \\
\text { Miquel }\end{array}$} & \multicolumn{2}{|c|}{ L1 - Sa Vall } & \multicolumn{2}{|c|}{$\begin{array}{l}\text { L2 - Ses } \\
\text { Pastores }\end{array}$} & \multicolumn{2}{|c|}{ TOTAL } \\
\hline & & AHN & DHN & AHN & DHN & AHN & DHN & AHN & DHN & AHN & DHN \\
\hline Good & $0-10$ & 0 & 36 & 0 & 55 & 13 & 47 & 0 & 10 & 8 & 40 \\
\hline Acceptable & $11-20$ & 0 & 21 & 50 & 18 & 3 & 31 & 0 & 20 & 8 & 25 \\
\hline Suspect & $21-50$ & 0 & 7 & 33 & 9 & 31 & 19 & 30 & 50 & 28 & 19 \\
\hline Poor & $>50$ & 100 & 36 & 17 & 18 & 53 & 3 & 70 & 20 & 57 & 15 \\
\hline \multicolumn{10}{|c|}{ Uncertainty components } & & \\
\hline \multicolumn{2}{|c|}{$\varepsilon 1$} & 16.4 & 5.9 & 13.3 & 5.7 & --- & 6.8 & --- & 5.6 & & \\
\hline \multicolumn{2}{|c|}{$\varepsilon 2$} & 274 & 28.3 & 28.3 & 22.4 & 48.8 & 17.3 & 64.0 & 37.3 & & \\
\hline \multicolumn{2}{|c|}{ Total } & 290.4 & 34.2 & 41.6 & 28.1 & 48.8 & 24.1 & 64.0 & 42.9 & & \\
\hline
\end{tabular}


Table 4. Maximum and average discharge as well as total contribution at event scale in the M2 - Sant Miquel, L1 - Sa Vall and L2 - Ses Pastores gauging stations applying the discharge transformation according to the stage-discharge rating curves and its uncertainty band of AHN and DHN.

\begin{tabular}{|c|c|c|c|c|c|c|c|c|c|c|c|c|c|c|c|c|}
\hline \multirow{2}{*}{$\begin{array}{l}\text { Magnitude } \\
\text { type of the } \\
\text { events }\end{array}$} & \multirow{2}{*}{$\begin{array}{c}\text { Gauging } \\
\text { station }\end{array}$} & \multirow{2}{*}{ Event } & \multirow{2}{*}{$\begin{array}{l}\text { Rating } \\
\text { curve }\end{array}$} & \multirow{2}{*}{$\begin{array}{c}\text { Maximum } \\
\text { water } \\
\text { stage }(m)\end{array}$} & \multicolumn{3}{|c|}{$Q_{\max }\left(m^{3} s^{-1}\right)$} & \multirow{2}{*}{$\begin{array}{c}\text { Measured } \\
\text { AHN - } \\
\text { DHN } \\
\text { ratio }\end{array}$} & \multicolumn{3}{|c|}{$Q_{\text {average }}\left(m^{3} s^{-1}\right)$} & \multirow{2}{*}{$\begin{array}{c}\text { Measured } \\
\text { AHN - } \\
\text { DHN } \\
\text { ratio }\end{array}$} & \multicolumn{3}{|c|}{$E_{w y}\left(h^{3}\right)$} & \multirow{2}{*}{$\begin{array}{c}\text { Measured } \\
\text { AHN - } \\
\text { DHN } \\
\text { ratio }\end{array}$} \\
\hline & & & & & $\begin{array}{l}\text { Low } \\
\text { band }\end{array}$ & $\begin{array}{l}\text { High } \\
\text { band }\end{array}$ & Measured & & $\begin{array}{l}\text { Low } \\
\text { band }\end{array}$ & $\begin{array}{l}\text { High } \\
\text { band }\end{array}$ & Measured & & $\begin{array}{l}\text { Low } \\
\text { band }\end{array}$ & $\begin{array}{l}\text { High } \\
\text { band }\end{array}$ & Measured & \\
\hline \multirow{6}{*}{ High } & \multirow{2}{*}{$\begin{array}{c}\text { Sant } \\
\text { Miquel }\end{array}$} & \multirow[b]{2}{*}{$29 / 09 / 2014$} & AHN & 1.03 & 4.960 & 12.110 & 8.552 & \multirow{2}{*}{35} & 0.444 & 1.084 & 0.838 & \multirow{2}{*}{24} & 0.051 & 0.125 & 0.087 & \multirow{2}{*}{31} \\
\hline & & & DHN & 1.15 & 17.780 & 31.633 & 24.694 & & 2.511 & 4.468 & 3.488 & & 0.206 & 0.366 & 0.286 & \\
\hline & \multirow{2}{*}{ Sa Vall } & \multirow{2}{*}{$28 / 11 / 2007$} & AHN & 13 & 3.524 & 10.283 & 6.910 & \multirow{2}{*}{61} & 1.800 & 5.252 & 3.688 & \multirow{2}{*}{92} & 0.468 & 1.366 & 0.856 & \multirow{2}{*}{92} \\
\hline & & & DHN & 2.10 & 8.613 & 14.064 & 11.332 & & 2.816 & 4.599 & 3.988 & & 0.733 & 1.196 & 0.926 & \\
\hline & \multirow{2}{*}{$\begin{array}{c}\text { Ses } \\
\text { Pastores }\end{array}$} & \multirow[b]{2}{*}{$22 / 11 / 2007$} & $\mathrm{AHN}$ & \multirow{2}{*}{1.62} & 4.288 & 19.533 & 11.911 & \multirow{2}{*}{253} & 0.597 & 2.720 & 1.658 & \multirow{2}{*}{281} & 0.311 & 1.415 & 0.861 & \multirow{2}{*}{281} \\
\hline & & & DHN & & 2.686 & 6.735 & 4.713 & & 0.337 & 0.844 & 0.591 & & 0.175 & 0.439 & 0.307 & \\
\hline \multirow{6}{*}{ Low } & \multirow{2}{*}{$\begin{array}{c}\text { Sant } \\
\text { Miquel }\end{array}$} & \multirow{2}{*}{$04 / 11 / 2014$} & AHN & 0.09 & 0.154 & 0.377 & 0.267 & \multirow{2}{*}{17} & 0.091 & 0.222 & 0.156 & \multirow{2}{*}{17} & 0.005 & 0.011 & 0.008 & \multirow{2}{*}{40} \\
\hline & & & DHN & 0.19 & 1.110 & 1.975 & 1.542 & & 0.656 & 1.168 & 0.912 & & 0.014 & 0.025 & 0.020 & \\
\hline & Sa Vall & $20 / 02 / 2008$ & AHN & 0.59 & 0.651 & 1.898 & 1.276 & 276 & 0.389 & 1.135 & 0.763 & 315 & 0.008 & 0.025 & 0.016 & 315 \\
\hline & & & DHN & & 0.351 & 0.573 & 0.462 & & 0.184 & 0.300 & 0.242 & & 0.004 & 0.006 & 0.005 & \\
\hline & Ses & & AHN & 0.42 & 0.199 & 0.908 & 0.554 & 317 & 0.053 & 0.243 & 0.148 & 335 & 0.015 & 0.067 & 0.041 & 336 \\
\hline & Pastores & $05 / 10 / 2007$ & DHN & & 0.100 & 0.250 & 0.175 & & 0.025 & 0.063 & 0.044 & | & 0.007 & 0.017 & 0.012 & 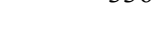 \\
\hline
\end{tabular}


Table 5. Annual water contribution, maximum and average discharge as well as relative difference at the M1 - Comafreda, M2 - Sant Miquel, L1 Sa Vall and L2 - Ses Pastores gauging stations applying the stage-discharge rating curves and its uncertainty band from AHN and DHN.

\begin{tabular}{|c|c|c|c|c|c|c|c|c|c|c|c|c|c|}
\hline \multirow[b]{2}{*}{$\begin{array}{c}\text { Gauging } \\
\text { station }\end{array}$} & \multicolumn{4}{|c|}{$Q_{\max }\left(m^{3} s^{-1}\right)$} & \multirow[b]{2}{*}{$\begin{array}{c}\text { Measured } \\
\text { AHN-DHN } \\
\text { ratio } \\
\end{array}$} & \multicolumn{3}{|c|}{$Q_{\text {average }}\left(m^{3} s^{-1}\right)$} & \multicolumn{5}{|c|}{$A_{w y}\left(h^{3}\right)$} \\
\hline & $\begin{array}{c}\text { Rating } \\
\text { curve }\end{array}$ & $\begin{array}{l}\text { Low } \\
\text { band }\end{array}$ & $\begin{array}{l}\text { High } \\
\text { band }\end{array}$ & Measured & & $\begin{array}{l}\text { Low } \\
\text { band }\end{array}$ & $\begin{array}{l}\text { High } \\
\text { band }\end{array}$ & Measured & $\begin{array}{c}\text { Measured } \\
\text { AHN-DHN } \\
\text { ratio } \\
\end{array}$ & $\begin{array}{l}\text { Low } \\
\text { band }\end{array}$ & $\begin{array}{l}\text { High } \\
\text { band }\end{array}$ & Measured & $\begin{array}{c}\text { Measured } \\
\text { AHN-DHN } \\
\text { ratio } \\
\end{array}$ \\
\hline \multirow{2}{*}{$\begin{array}{c}\text { M1 - } \\
\text { Comafreda }\end{array}$} & $\mathrm{AHN}$ & -- & 2.324 & 0.801 & & -- & 0.025 & 0.007 & & -- & 0.776 & 0.267 & \\
\hline & DHN & 13.879 & 28.220 & 21.028 & & 0.043 & 0.087 & 0.065 & & 1.354 & 2.752 & 2.051 & \\
\hline \multirow{2}{*}{$\begin{array}{c}\text { M2 - Sant } \\
\text { Miquel }\end{array}$} & AHN & 4.960 & 12.110 & 8.552 & \multirow{2}{*}{35} & 0.183 & 0.446 & 0.312 & \multirow{2}{*}{63} & 5.767 & 14.079 & 9.412 & \multirow{2}{*}{60} \\
\hline & DHN & 17.780 & 31.633 & 24.694 & & 0.356 & 0.633 & 0.494 & & 11.223 & 19.967 & 15.587 & \\
\hline \multirow{2}{*}{ L1 - Sa Vall } & AHN & 3.524 & 10.283 & 6.910 & \multirow{2}{*}{61} & 0.195 & 0.569 & 0.382 & \multirow{2}{*}{200} & 6.165 & 17.986 & 12.088 & \multirow{2}{*}{200} \\
\hline & DHN & 8.613 & 14.064 & 11.332 & & 0.145 & 0.237 & 0.191 & & 4.587 & 7.490 & 6.035 & \\
\hline \multirow{2}{*}{$\begin{array}{l}\text { L2 - Ses } \\
\text { Pastores }\end{array}$} & AHN & 3.910 & 17.939 & 10.850 & \multirow{2}{*}{235} & 0.374 & 1.704 & 1.039 & \multirow{2}{*}{294} & 11.827 & 53.881 & 32.854 & \multirow{2}{*}{294} \\
\hline & DHN & 2.430 & 6.093 & 4.624 & & 0.201 & 0.505 & 0.353 & & 6.367 & 15.961 & 11.170 & \\
\hline
\end{tabular}


1 Table 6. Annual water contribution, maximum and average discharge as well as relative difference at the

2 M1 - Comafreda, M2 - Sant Miquel, L1 - Sa Vall and L2 - Ses Pastores gauging stations applying the stage-

3 discharge rating curves of $\mathrm{AHN}$ and $\mathrm{DHN}$.

4

\begin{tabular}{|c|c|c|c|c|c|c|c|}
\hline \multirow{2}{*}{ M1 - Comafreda } & AHN & 0.267 & \multirow{2}{*}{13} & 0.801 & \multirow{2}{*}{4} & 0.007 & \multirow{2}{*}{11} \\
\hline & DHN & 2.051 & & 21.028 & & 0.065 & \\
\hline M2 - Sant Miquel & $\mathrm{AHN}$ & 9.412 & 60 & 8.552 & 35 & 0.312 & 63 \\
\hline \multirow{2}{*}{ L1 - Sa Vall } & AHN & 12.088 & \multirow{2}{*}{200} & 6.910 & \multirow{2}{*}{61} & 0.382 & \multirow{2}{*}{200} \\
\hline & DHN & 6.035 & & 11.332 & & 0.191 & \\
\hline \multirow{2}{*}{ L2 - Ses Pastores } & AHN & 32.854 & \multirow{2}{*}{294} & 10.850 & \multirow{2}{*}{235} & 1.039 & \multirow{2}{*}{294} \\
\hline & DHN & 11.170 & & 4.624 & & 0.353 & \\
\hline
\end{tabular}

5 